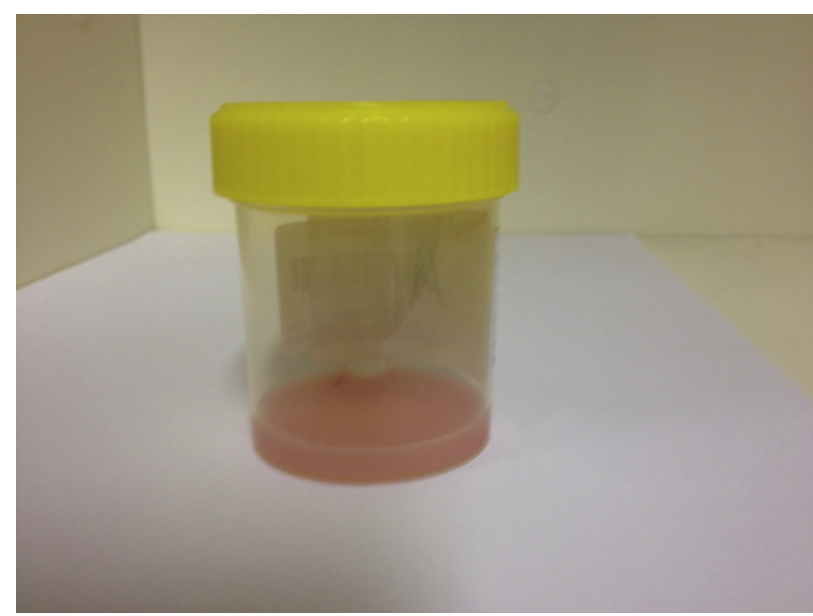

FIGURE 1. Chylous pleural fluid sample.

Symptoms will include expectoration of milky-white, foul-tasting sputum. However, the degree of production will be variable and not necessarily postprandial or linked with fatty food consumption. Lymphangiograms can aid in the diagnosis, although this is dependent on the speed of accumulation of the chyle leak. Where it is not available, radionuclide lymphoscintigraphy, normally reserved for imaging of malignant disease or lymphedema of the extremities, also can be used to visualize abnormalities of the thoracic duct. ${ }^{4}$

\section{CONCLUSIONS}

Iatrogenic injury to the thoracic duct is a not an uncommon consequence of thoracic cavity surgery. We present a case of such an injury after distal aortic arch repair, with persistent chylothorax and chyloptysis as a consequence.

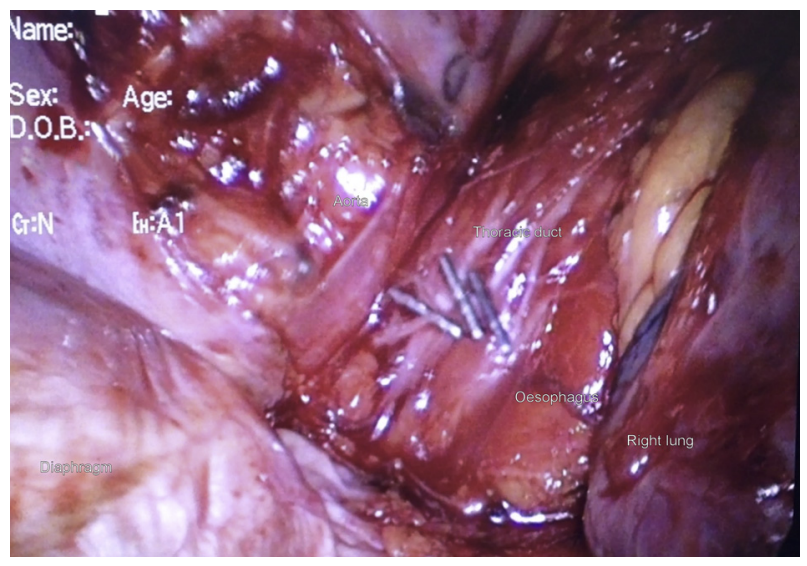

FIGURE 2. Thoracic duct ligation at video-assisted thoracic surgery.

Although the preference of the original treating surgeon was to attempt surgical correction via redo thoracotomy, in this case right-assisted video-assisted thoracoscopy duct ligation was used as a successful conclusive treatment modality. Because video-assisted thoracic surgery has a relatively low morbidity and cost, earlier use of this approach is supported by the literature. ${ }^{5}$

\section{References}

1. Staats BA, Ellefson RD, Budahn LL, Dines DE, Prakash UB, Offord K. The lipoprotein profile of chylous and nonchylous pleural effusions. Mayo Clinc Proc. 1980;55:700-4.

2. Lim KG, Rosenow EC, Staats B, Couture C, Morgenthaler TI. Chyloptysis in adults. Chest. 2004;125:336-40.

3. Tregunna R, Belcher E, Cane P. An unusual case of chyloptysis. J Thorac Cardiovasc Surg. 2011;142:e2-3.

4. Baulieu F, Baulieu J, Mesny J, Ducouret N, Benhamou A. Visualization of the thoracic duct by lymphoscintigraphy. Eur J Nucl Med. 1987;13:264-5.

5. Fahimi H, Casselman FP, Mariani MA, van Boven WJ, Knaepen PJ. Current management of postoperative chylothorax. Ann Thorac Surg. 2001;71:448-51.

\title{
Lung transplant in Jehovah's Witness patient
}

\author{
Francisco Cerezo Madueño, MD, Elisabet Arango Tomás, MD, and Ángel Salvatierra Velázquez, MD, \\ Córdoba, Spain
}

\footnotetext{
From the Thoracic Surgery and Lung Transplantation Unit, University Hospital Reina Sofía, Córdoba, Spain.

Disclosures: Authors have nothing to disclose with regard to commercial support.

Received for publication Dec 4, 2012; revisions received Jan 31, 2013; accepted for publication Feb 14, 2013; available ahead of print March 13, 2013.

Address for reprints: Elisabet Arango Tomás, MD, Division of Thoracic Surgery and Lung Transplantation, Reina Sofía University Hospital, Avda Menéndez Pidal s/n 14004-Córdoba, Spain (E-mail: eli_piano@ hotmail.com).

J Thorac Cardiovasc Surg 2013;145:e65-7

$0022-5223 / \$ 36.00$

Copyright (c) 2013 by The American Association for Thoracic Surgery

http://dx.doi.org/10.1016/j.jtcvs.2013.02.043
}

Studying transplant candidates can be difficult, especially if the patient states that he or she cannot accept homologous blood products, such as Jehovah's Witnesses. This has been discussed in the medical literature ${ }^{1}$; however, there are only 2 documented cases of lung transplantation (LT). ${ }^{2,3}$ We present the first right single $\mathrm{LT}$ for emphysema-type chronic obstructive pulmonary disease (COPD) in a man who is a Jehovah's Witness. 

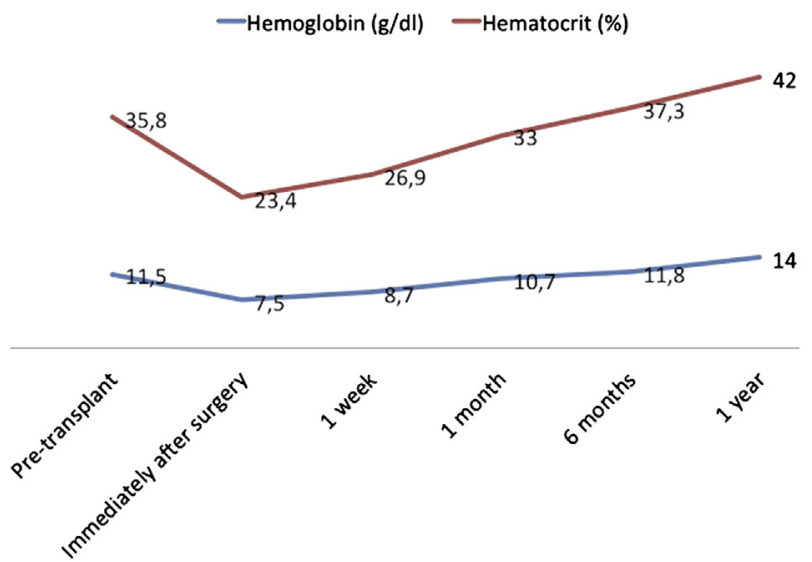

FIGURE 1. Chart of postoperative follow-up of patient's hematocrit.

\section{CLINICAL SUMMARY}

A 56-year-old man with terminal emphysema-type COPD was accepted as a right single LT candidate. The patient stated from the outset that he could not accept any kind of blood product for religious reasons. His functional test results were as follows: partial pressure of oxygen $=62$ $\mathrm{mm} \mathrm{Hg}$, partial pressure of carbon dioxide $=68 \mathrm{~mm} \mathrm{Hg}$, forced vital capacity $=2180 \mathrm{~mL}(51.1 \%)$, and forced expiratory volume in 1 second $=520 \mathrm{~mL}(16.4 \%)$. No steps were taken to increase the hemoglobin pretransplant because transplantation is an unpredictable procedure and intraoperative bleeding risk for single LT for COPD is comparable to that for pneumonectomy.

A right single LT was performed, with an ischemic time of 340 minutes. No extracorporeal circulation was required, and there were no intraoperative complications. Attention was given at all times to hemostatic technique. No cellsaver or antifibrinolytic drugs were used intraoperatively. During surgery, we administered ascorbic acid $500 \mathrm{mg}$ before reperfusion systematically with $\mathrm{N}$-acetylcysteine and methylprednisolone.

In the early intensive care unit (ICU) phase, the patient had anemia. A weekly dose of erythropoietin was administered with vitamin C $1 \mathrm{~g} / 24$ hours for 13 days and iron(II) lactate for 23 days to support the patient's hematocrit postoperatively (Figure 1). Postoperative functional test results were as follows: partial pressure of oxygen $=385 \mathrm{~mm} \mathrm{Hg}$, partial pressure of carbon dioxide $=47.4 \mathrm{~mm} \mathrm{Hg}$, and oxygenation index $=385$. Respiratory physiotherapy was instituted from the ICU, and the patient remained there for 13 days. The patient remained in the hospital 35 days. He presented the following complications: an episode of acute rejection and pneumonia. Immunosuppressive therapy consisted of cyclosporine A, mycophenolate mofetil, and corticoids. Medical follow-up was instituted, and the patient had no marrow suppression. At 18 months of follow-up, the
TABLE 1. Comparison between our case and the 2 previously published cases

\begin{tabular}{|c|c|c|c|}
\hline & $\begin{array}{c}\text { Conte and Orens }{ }^{2} \\
\text { (1999) }\end{array}$ & $\begin{array}{c}\text { Grande et } \mathrm{al}^{3} \\
(2003)\end{array}$ & $\begin{array}{c}\text { Cerezo } \\
\text { Madueño et al } \\
(\mathbf{2 0 1 3})\end{array}$ \\
\hline Age, y & 48 & 38 & 56 \\
\hline Gender & Female & Female & Male \\
\hline Pathology & IPF & IPF & COPD \\
\hline $\begin{array}{l}\text { Secondary } \\
\text { pulmonary } \\
\text { hypertension }\end{array}$ & Yes & No & No \\
\hline $\begin{array}{l}\text { Type of } \\
\text { transplant }\end{array}$ & Left single lung & Left single lung & Right single lung \\
\hline Survival & $?$ & $\begin{array}{c}14 \text { mo (acute } \\
\text { rejection) }\end{array}$ & $25 \mathrm{mo}$ \\
\hline
\end{tabular}

$\overline{I P F}$, Idiopathic pulmonary fibrosis; $C O P D$, chronic obstructive pulmonary disease.

patient was asymptomatic, with a good quality of life and performance status. The patient has since died, 25 months after receiving the transplant, having developed obstructive bronchial syndrome 7 months before death.

\section{DISCUSSION}

Jehovah's Witnesses do not believe in accepting homologous blood or blood products. In transplant candidates who are Jehovah's Witnesses, a number of conflicting moral issues arise, and we need to reflect and seek well-founded and coherent solutions that can help us make decisions. On the basis of the universal principles of our code of medical ethics, we justify the intercultural and transcultural decisions. ${ }^{4}$ Solutions to problems of a moral nature require careful thought supported by professional experience. ${ }^{1}$ It is morally unacceptable to put the life of a patient at risk if there are conservative resources. Furthermore, the autonomy of a patient who accepts a transplant on the condition that no blood will be administered if necessary should be respected. Several authors have published their experience regarding the possibility of minimizing blood loss and avoiding blood transfusions when studying issues related to organ transplantation in patients who are Jehovah's Witnesses $^{5}$; however, cases of LT are scarce ${ }^{2,3}$ (Table 1).

We believe that it is necessary to select the patients in such cases. There is no clinical experience in double LT for Jehovah's Witnesses. Double LT increases blood loss and the need for a blood transfusion. Single LT generally has fewer intraoperative complications than double LT with fewer transfusions and extracorporeal circulation. In addition, our experience shows that pulmonary emphysema, which is the most frequent reason for transplantation, is usually the least problematic surgically and postoperative care is usually better tolerated. Intraoperative bleeding risk for single LT in a patient with COPD is comparable to that for pneumonectomy. In our case, the risk of anemia/hemorrhage was 
less than the risk of respiratory failure. Thus, single LT may be chosen for cases with low bleeding risk, such as COPD. However, some measures should be taken for double LT: decrease the time on the waiting list (emergency code), increase the pretransplant hemoglobin (erythropoietin), and consider preoperative self-donation. Multiple transfusions can be required given the marrow-suppressing effect of the medications and anemia of chronic disease. These were not present in our case, but they could be treated with erythropoietin and pharmacologic efforts.

From the beginning of our LT program in October of 1993, we have performed approximately 400 LTs. In the last 10 years, 70 LTs were for COPD, and the patients remained in the ICU for 12 days and the hospital for 45 days. The described case was within normal ranges, and these results may be due to Spain's social and health services system.

\section{CONCLUSIONS}

Our case showed that LT can be performed safely in Jehovah's Witnesses and offers a new perspective when deciding whether to perform major surgery and at the same time comply with the conditions that Jehovah's Witnesses follow, allowing for LT to be performed in patients who otherwise would have been excluded from the list of candidates.

\section{References}

1. Elmistekawy E, Mesana TG, Ruel M. Should Jehovah's Witness patients be listed for heart transplantation? Interact Cardiovasc Thorac Surg. 2012;15:716-9.

2. Conte JV, Orens JB. Lung transplantation in a Jehovah's Witness. J Heart Lung Transplant. 1999;18:796-800.

3. Grande AM, Rinaldi M, D'Armini AM, Pellegrini C, Viganò M. Lung transplantation in a Jehovah's witness. Case report in a twinning procedure. J Cardiovasc Surg (Torino). 2003;44:131-4.

4. Beauchamp TL. Methods and principles in biomedical ethics. J Med Ethics. 2003 29:269-74

5. Mallory GB Jr. Challenging issues associated with organ transplantation for Jehovah's Witness individuals. J Heart Lung Transplant. 2000;19:119-20.

\title{
Acute bilateral pulmonary embolism and complete occlusion of the left internal carotid artery caused by paradoxical embolus through a persistent foramen ovale in a 32-year-old woman
}

\author{
Brigitte Gansera, MD, ${ }^{\mathrm{a}}$ Michael Bauer, MD, ${ }^{\mathrm{b}}$ Laura Gansera, ${ }^{\mathrm{a}}$ and Walter Eichinger, MD, PhD, ${ }^{\mathrm{a}}$ Munich, \\ Germany
}

In 1877 , Cohnheim ${ }^{1}$ was the first to report a case of paradoxical embolism. $\mathrm{Zahn}^{2}$ described the first patient in which necropsy revealed a thrombus localized in the foramen ovale. Cerebrovascular accidents caused by paradoxical embolism through a persistent foramen ovale are rare, but have been described as a reason for them, especially in young patients with no other risk factors. ${ }^{3}$ We describe, to our knowledge, a unique case of a 32year-old woman with pulmonary embolism and occlusion of the left internal and external carotid arteries caused by paradoxical embolism through a patent foramen ovale (PFO).

\footnotetext{
From the Department of Cardiovascular Surgery ${ }^{\mathrm{a}}$ and the Department of Radiology, ${ }^{\mathrm{b}}$ Klinikum Bogenhausen, Munich, Germany.

Disclosures: Authors have nothing to disclose with regard to commercial support.

Received for publication Jan 13, 2013; revisions received Feb 10, 2013; accepted for publication Feb 27, 2013; available ahead of print March 26, 2013.

Address for reprints: Brigitte Gansera, MD, Department of Cardiovascular Surgery, Clinic Bogenhausen, Munich, Englschalkingerstr. 77, 81925 Munich, Germany (E-mail: brigitte_gansera@web.de).

J Thorac Cardiovasc Surg 2013;145:e67-9

$0022-5223 / \$ 36.00$

Copyright (C) 2013 by The American Association for Thoracic Surgery

http://dx.doi.org/10.1016/j.jtcvs.2013.02.054
}

\section{CLINICAL SUMMARY}

A 32-year-old woman with clinical signs of right-side hemiplegia, aphasia, and dyspnea was transferred urgently from the stroke unit of another hospital to our department of cardiac surgery. The day before, the patient experienced an isolated, sudden occurrence of right-hand paresthesia and dizziness. She also complained of left-side leg pain, without other previous symptoms. Risk factors for deep venous thrombosis were oral contraceptives, smoking, and extreme obesity (body mass index, 50).

Computed tomography (CT)-angiography was performed and sagittal sinus thrombosis was detected. Duplex ultrasound of the extremities showed thrombosis of the right and left femoral veins. Initially, the patient received a bolus of $5000 \mathrm{IU}$ heparin followed by continuous administration of heparin (30,000 IU/24 hours). The next day the patient's neurologic symptoms worsened rapidly (right-side hemiplegia and aphasia) and were accompanied by dyspnea.

Additional duplex ultrasound and CT-angiography revealed complete occlusion of the left internal carotid artery (Figure 1); the vertebral arteries were normal. Transcranial ultrasound showed collateralization via the communicating artery from the right side to the left. At first, cerebral CT did not show any pathologic results. With the suspicion of 